\title{
Sensitivity of land-use pattern optimisation to variation in input data and constraints
}

\author{
A. Herzig ${ }^{\text {a }}$ A.-G.E. Ausseil a , J.R. Dymond ${ }^{\text {a }}$ \\ ${ }^{a}$ Landcare Research New Zealand Ltd, Private Bag 11052, Palmerston North 4442, New Zealand \\ Email: herziga@landcareresearch.co.nz
}

\begin{abstract}
Spatial optimisation has been widely used in scientific studies for land-use pattern optimisation and resource allocation, often to maximise ecosystem services and/or land use performances. Such use implies its applicability in real-world spatial planning and policy development. But how suitable is spatial optimisation, especially in the context of uncertain input data and stakeholder expectations? For example, what is the impact of uncertainty associated with modelled nitrate leaching rates on land-use pattern optimisation with the objective to minimise nitrate leaching? Since spatial optimisation problems are usually constrained by stakeholder expectations or preferences, it is equally important to know how sensitive optimal land-use pattern are to changes in those expectations and preferences.
\end{abstract}

In this paper, we investigate how sensitive optimal land-use patterns are to variation in input data (e.g. nitrate leaching rates) and optimisation constraints, such as stakeholder expectations in terms of agricultural production outputs. Our analysis was based on a spatial optimisation study in the Hawke's Bay area of New Zealand's North Island. The objective was to explore the landscape's limits in terms of the potential reduction in nitrate leaching. The optimisation problem was constrained by expectations for agricultural production outputs of the main agricultural land uses in this area. The spatial optimisation was based on nitrate leaching rates for each land use-land parcel combination of the case study area. Since no information was available on the uncertainties associated with the given nitrate leaching rates, we computed seven different optimisation scenarios, assuming seven different levels of uncertainties ranging from 5\% to $50 \%$. For each of those seven scenarios, we computed 500 optimisation runs and added to each run a uniformly distributed random error to the given nitrate leaching values. We then determined the allocation frequency of each land use to each land parcel for each uncertainty level. Based on the allocation frequencies, we determined the maximum allocation probability for each land parcel and uncertainty level, which represents the most likely allocated land use over 500 optimisation runs. The distributions of allocation probabilities across land parcels as well as across uncertainty levels were then used to characterise the sensitivity of the optimal land-use pattern to variation in the underlying nitrate leaching rates. To compare the landscape's potential to reduce nitrate leaching across the different uncertainty levels, we calculated the mean total nitrate leaching for the case study area for each uncertainty level (i.e. across 500 optimisation runs) and associated it with the mean maximum allocation probability for the particular uncertainty level. To analyse the impact of variation in the optimisation constraints on the optimal land-use pattern, we followed a similar approach. But instead of a random perturbation like with the nitrate leaching rates, we systematically varied the optimisation constraints by values ranging from $+50 \%$ to $-50 \%$ to compute a total of 14 different optimisation scenarios. However, only nine scenarios with values ranging from +10 to $-50 \%$ actually represented feasible optimisation problems and yielded an optimal land-use configuration. To characterise the variation in the generated optimal land-use pattern, we also derived allocation probabilities, which referred to the nine feasible optimisation scenarios featuring different optimisation constraints.

The results of the optimisation scenarios show that the potential reduction of total nitrate leaching increases with the uncertainty of the modelled nitrate leaching rates. Hence, the spatial optimisation potential increases with the variance of the input data. The mean maximum allocation probability decreased with higher uncertainty of the input data. The observed sensitivity of the land-use configuration to variation of the optimisation constraints is in general smaller than the observed sensitivity for the variation of input data. Uncertainty of input performance scores for spatial optimisation can lead to an overestimation of the actual benefit of spatial optimisation. In the Heretaunga case study area the potential spatial optimisation benefit was overestimated by more than $5 \%$ points for uncertainty levels of more than $20 \%$. Uncertainty associated with the optimisation performance scores had overall greater impact on the uncertainty of optimal land-use allocation than the variation of optimisation constraints. Maps of maximum allocation probabilities help spatial planners identify hot spot areas for targeted land-use development and change.

Keywords: Land-use pattern, Sensitivity, Spatial optimisation, Allocation probability, LUMASS 


\section{INTRODUCTION}

Spatial optimisation has been widely used in scientific studies for land-use pattern optimisation and resource allocation. In general, the aim is to maximise ecosystem services and/or land-use performances (e.g. Seppelt and Voinov, 2002; Groot et al., 2008; Herzig, 2008, Meyer and Grabaum, 2008; Polsaky et al., 2008; Ausseil et al., 2012, Lautenbach et al., 2012; Herzig et al., in press). The variation of spatial optimisation results is often analysed and discussed on an aggregate level, e.g. looking at the whole area of interest. For example, the analysis of the 'pareto-front', generated by search heuristics such as genetic algorithms or simulated annealing, is often only displayed as aggregate scatter plots for a whole region (e.g. Lautenbach et al., 2012), thus hiding spatial variation and detail. Only a few studies have investigated the impact of uncertain or varying input data on the actual spatial result of spatial optimisation (Aerts et al., 2003; Murray, 2003; Beech et al., 2008; Wei and Murray, 2012). In this paper, we investigate the sensitivity of optimal land-use maps generated by optimisation algorithms to variation of input data and optimisation constraints. This is of particular relevance to the applicability of these maps to inform real-world spatial planning and policy development. For example, a relatively stable pattern indicates a larger degree of freedom in terms of planning alternatives, whereas a relatively unstable pattern indicates there is not much room for trade-offs without significantly changing expectations (i.e. constraints). In the remainder of the paper we introduce the case study area and available data (Section 2), describe the methodological approach of the investigation (Section 3), present preliminary results of our findings as well as discuss potential implications for spatial planning (Section 4), and provide concluding remarks (Section 5).

\section{HERETAUNGA CASE STUDY AREA}

The investigation is based on a land-use optimisation study we conducted in the Hawke's Bay area on the North Island of New Zealand. The goal of the study was to support the implementation of the region's Land and Water Management Strategy as well as the establishment of water quality limits by land-use optimisation scenarios (Herzig et al., 2013). The Heretaunga case study area is dominated by pastoral farming, which comprises $\sim 52 \%$ of the total area (Table 1 ). Approximately $33 \%$ of the area is covered by native bush and scrub. The remaining $15 \%$ of the case study area includes forestry, horticulture, and other land uses. Clean water provision in the region is affected by nitrate leaching from the soil into water bodies, which occurs at different rates under individual farming and cropping land uses (Dymond et al., 2013). The magnitude of nitrate leaching depends on the number and type of livestock, and on fertiliser application rates (Beukes et al., 2012). It also depends on soil characteristics, for example, a shallow stony soil is more likely to leach nitrate than a deep loamy soil. To explore the landscape's limits with regard to nitrate leaching reduction potential in the Heretaunga case study area, we optimised the land-use pattern to minimise nitrate leaching. Because of the high importance of agricultural land use in the area, we constrained the spatial optimisation to produce the same agricultural output as from the reference land-use configuration of 2011. Considered agricultural outputs in this case study were i) potential meat production (kg $\mathrm{ha}^{-1}$ ) from sheep and beef, sheep, beef, and deer; ii) wool production ( $\mathrm{kg} \mathrm{ha}^{-1} \mathrm{yr}^{-1}$ ) from sheep and beef, and sheep; iii) production of milk solids ( $\mathrm{kg} \mathrm{ha}^{-1} \mathrm{yr}^{-1}$ ) from dairying; iv) wood production ( $\mathrm{t} \mathrm{ha}^{-1} \mathrm{yr}^{-1}$ ) from forestry; v) production of apples $(\mathrm{t}$ $\mathrm{ha}^{-1} \mathrm{yr}^{-1}$ ) from pipfruit; and vi) production of grapes ( $\left.\mathrm{ha}^{-1} \mathrm{yr}^{-1}\right)$ from viticulture. The input data for the optimisation scenarios, i.e. the nitrate-leaching rate per unit area, for each individual land use-land parcel combination, as well as the agricultural output data, were derived from different sources. Nitrate leaching rates for pastoral farming were adopted from a national-scale assessment by Dymond et al. (2013). There, nitrate-N leaching per animal was estimated separately for sheep, beef cattle, dairy cattle, and deer using the OVERSEER ${ }^{\circledR}$ (Ledgard and Waller, 2001) model for 100 unique soil and climate combinations of New Zealand (i.e. Land Environments New Zealand level II, Leathwick et al., 2003). Stock-carrying capacity at farm scale (Ministry of Works and Development, 1981) was then used to estimate nitrate leaching rates $\left(\mathrm{kg} \mathrm{N} \mathrm{ha}^{-1} \mathrm{yr}^{-1}\right)$ for individual land parcels (i.e. polygons in Figure 1). For arable cropping the nitrate leaching

Table 1. Land-use/land-cover classification and area share of the Heretaunga case study area as at 2011. Land-use/land-cover classes marked with an asterix (*) were not considered for re-allocation as part of the optimisation scenarios.

\begin{tabular}{|l|r|r|}
\hline & Area (ha) & $\begin{array}{r}\text { Area } \\
\text { share } \\
\text { (\%) }\end{array}$ \\
\hline Sheep and beef & 121705 & 38 \\
\hline $\begin{array}{l}\text { Scrub } \\
\text { (Mānuka/Kānuka)* }\end{array}$ & 54247 & 17 \\
\hline Native bush* & 49592 & 16 \\
\hline Forestry & 23360 & 7 \\
\hline Beef & 20481 & 6 \\
\hline Sheep & 12982 & 4 \\
\hline Dairy & 8530 & 3 \\
\hline Pipfruit & 7911 & 2 \\
\hline Viticulture & 5120 & 2 \\
\hline Cropping & 3616 & 1 \\
\hline Deer & $\mathbf{3 1 9} \mathbf{0 6 3}$ & $\mathbf{1 0 0}$ \\
\hline Other* & & 1 \\
\hline Total &
\end{tabular}


rate was assumed to be twice that estimated for sheep at stock-carrying capacity (Lilburne et al., 2010). Nitrate leaching rates for viticulture and pipfruit were extrapolated from modelled values of an adjacent area (Herzig et al., 2013). Agricultural output estimates for pastoral farming and forestry are based on Ausseil et al. (2013), whereas estimates for pipfruit and viticulture were adopted from Herzig et al. (2013). In absence of available output estimates for arable cropping, we constrained this sector to maintain its area share throughout the optimisation scenarios. The number and type of different input sources suggest that the optimisation performance scores (i.e. nitrate leaching and agricultural output) are afflicted with varying degrees of uncertainties. Also, the agricultural output constraints are subject to variation, since they do not necessarily represent the view of all involved stakeholders in the region. Furthermore, they do not reflect any potential for agricultural growth (Ausseil et al., 2013).

\section{LAND-USE PATTERN OPTIMISATION UNDER INPUT DATA VARIATION}

To support regional planning and policy development adequately in the region, we investigated the influence of variation of input performance scores (i.e. nitrate leaching rates) and optimisation constraints on the spatial land use pattern produced by the optimisation algorithm. In this study, variation of input performances scores stems from the uncertainties associated with nitrate leaching estimates for the land uses included in the optimisation procedure. However, we did not account for any uncertainties associated with the performance scores of the individual agricultural outputs considered in this case study. Since no measured nitrate leaching rates were available for the Heretaunga case study area, an adequate assessment of the error associated with the modelled nitrate leaching rates was not possible. Ledgard and Waller (2001) estimated an uncertainty of $\pm 20 \%$ of $\mathrm{N}$ leaching from pastoral farming modelled with OVERSEER ${ }^{\circledR}$. Taking into consideration that the nitrate leaching rates for pastoral farming were adopted from a national-scale assessment, which was based on a subset of the soil types in the case study area, the true uncertainty associated with those values is probably higher. No uncertainty estimates were available for the nitrate leaching rates adopted for the other land uses considered in this study. However, since they were based on assessments which were originally conducted for other study areas, it seems likely that the uncertainty associated with these values is at least as high as for the estimates for pastoral farming land uses. Furthermore, we assumed that the estimated nitrate leaching rates did not systematically deviate from the true values. Hence, we modelled the uncertainties associated with the input performance scores as non-systematic random errors (cf. Aerts et al., 2003). In the light of our main objective to explore the robustness of land-use pattern optimisation against uncertain input data, we also employed a wide range of error margins and computed optimal land-use patterns for different levels of uncertainties (i.e. 5\%, 10\%, 15\%, 20\%, 30\%, 40\%, and 50\%).

Optimisation constraints represent the expectations of stakeholders towards the landscape as regards certain criteria. The expectations are based on different preferences of how to develop a landscape, e.g. economic growth versus environmental protection. They are also based on expected future developments, e.g. the anticipated development of agricultural market and production conditions. Therefore, we modelled the uncertainty associated with optimisation constraints by systematically varying the given agricultural output constraints (cf. Section 2) from $-50 \%$ to $+50 \%$.

We evaluated the individual optimisation scenarios by means of the particular objective function results, which represent the total nitrate leaching $\left(\mathrm{kg} \mathrm{yr}^{-1}\right)$ from the considered land uses and land-use parcels of the case-study area. To assess the spatial impact of uncertain input data and constraints, we derived allocation probabilities for each individual land use to each individual land parcel and compared the probability maps with the reference land-use configuration of 2011 (Figure 1).

\subsection{Land-Use Pattern Optimisation}

We used the Land Use Management Support System (LUMASS) (Herzig, 2008, Herzig et al., in press) to generate optimal land use pattern for the individual optimisation scenarios. LUMASS employs the mixed integer linear programming solver lp_solve (Berkelaar et al., 2004) to allocate quantities of land use area (area shares) $\boldsymbol{x}$ of a set of land uses $L$ to a set of land parcels (i.e. polygons) $F$. In this case study, the allocation was subject to the estimated nitrate leaching rates $c$ for $v$ land use-land parcel combinations of the case study area. The objective function of each individual scenario was to minimise nitrate leaching:

$\min (\mathbf{c x})$

$$
\text { with } \boldsymbol{x} \in B \text {, where } B=\left\{\boldsymbol{x} \in \mathbb{R}^{v}: \boldsymbol{S} \boldsymbol{x} \geq \boldsymbol{b}, \boldsymbol{x} \geq 0, \boldsymbol{b} \in \mathbb{R}^{q}\right\}
$$

Stakeholder expectations $\boldsymbol{b}$ with regard to the $q$ agricultural outputs (cf. Section 2) produced from the landscape were represented as constraints of the optimisation problem:

$\sum_{d \in D} \sum_{u \in U} s_{d u j} x_{d u} \geq b_{U D j}$ with $x_{d u} \in \mathbb{R}, s_{d u j} \in \mathbb{R}, b_{U D j} \in \mathbb{R}, b_{U D j} \geq 0, U \subseteq L, D \subseteq F$ 
where $s_{d u j}$ is the performance of land use $u$ on parcel $d$ in terms of agricultural output $j$, and depends on the area share $x_{d u}$ of land use $u$ allocated to parcel $d$. We also constrained the total area share of land uses allocated to anyone land parcel to not exceed the land parcel's size:

$\sum_{u \in U} x_{d u}=A_{d} \quad$ with $x_{d u} \in \mathbb{R}, A_{d} \in \mathbb{R}, d \in D, U \subseteq L, D \subseteq F$

where $A_{d}$ denotes the size (ha) of land parcel $d$. Since only agricultural and forestry production land uses were considered to be re-allocated in the land-use optimisation scenarios (Table 1), the optimisation problem was restricted to the subset $U$ of land uses, which were allocated in the reference land-use configuration of 2011 to the subset $D$ of land parcels.

\subsection{Variation of input data}

To evaluate the influence of uncertainties associated with the input performance scores, we computed a series of optimisation scenarios, one for each of the seven different uncertainty levels ranging from 5\% to 50\% (Table 2). In each scenario, we added a random error, representing the particular uncertainty level, to the estimated nitrate leaching rates of each individual land use-land parcel combination. For example, for the $20 \%$ uncertainty level and a particular land use-land parcel combination, we added a uniformly distributed random error in the range of $-20 \%$ to $+20 \%$ of the estimated nitrate leaching rate of the particular land useland parcel combination. We then optimised the land-use pattern based on the perturbed performance scores. To cover adequately the variance of the optimisation results introduced by the random error, we computed 500 optimisation runs for each of the seven uncertainty levels. Then we determined the allocation frequency of each individual land use $u$ to each individual land parcel $d$ across the 500 optimisation runs and derived the allocation probability $p_{u d}$. The sensitivity or uncertainty of the land-use allocation with respect to the particular uncertainty level can then be expressed for each individual land parcel by $e_{u d}$ :

$e_{u d}=100-p_{u d}$

The land use with the highest (maximal) allocation probability or the smallest allocation uncertainty $e_{u d}$ for a given uncertainty level was considered to be the allocated land use to the particular land parcel. For the sake of readability, we will henceforth refer to the maximal allocation probability of a land use to a particular land parcel for a particular uncertainty level simply as the allocation probability. The overall certainty of the landuse allocation for the whole region and a particular uncertainty level can then be characterised by the distribution of land-use allocation probabilities (i.e. maximal allocation probabilities) to the considered land parcels of the case study area. The mean and maximum allocation probabilities for the considered land uses and land parcels indicate the overall uncertainty of the land-use allocation for a given uncertainty level.

\subsection{Variation of optimisation constraints}

We modelled the uncertainties associated with the optimisation constraints by systematically varying the given agricultural output constraints by a margin ranging from $-50 \%$ to $+50 \%$ of their individual reference value from 2011 and computed 14 different optimisation runs. Only nine of those runs in the range of $+10 \%$ to $-50 \%$ error margin produced feasible results (Table 3 ). Increasing the agricultural output constraints by more than $10 \%$ led to infeasible optimisation problems, i.e. no optimal land-use pattern could be generated. The 10\% increase represents the maximal achievable increase of agricultural outputs given the management practises (e.g. stocking density, fertiliser use) reflected by the individual performance scores with regard to agricultural outputs. In all cases, the optimisation runs were based on the modelled nitrate leaching rates of the reference land-use configuration of 2011 and did not include any uncertainty. To assess the impact of the constraints variation on the overall optimisation objective, we compared the total nitrate leaching from the considered land uses and land parcels of the Heretaunga case study area for each variation of the constraints. We also assessed the impact on the generated land-use pattern by deriving allocation probabilities (cf. Section 3.2) across the nine different optimal land-use configurations.

\section{RESULTS AND DISCUSSION}

\subsection{Optimal land-use pattern sensitivity to variation of input data}

Table 2 summarises the sensitivity of land-use pattern optimisation to variation of input data for the Heretaunga case-study area. It shows that the potential reduction of total nitrate leaching increases with the uncertainty of the modelled nitrate leaching rates. This indicates that the spatial optimisation potential increases with the variance of the input data. Depending on the source of the variance, this has different implications for spatial planning. Increased variance of performance scores due to uncertainties, leads to an 
overestimation of the potential performance change (gain) by spatial optimisation, whereas an increased variance due to greater spatial variability of performance scores indicates greater potential benefits by spatial optimisation. The mean allocation probability over all land parcels decreases with increased uncertainty from $81 \%$ to $72 \%$ (Table 2). At the same time, the number of different land uses allocated to individual land parcels over the 500 optimisation runs per uncertainty level increased from three to seven. This is also reflected by the decreasing minimum allocation probability with increasing uncertainty (Table 2). Overall, the distribution of allocation probabilities across uncertainty levels shows a shift towards smaller allocation probabilities. For example, for the $5 \%$ uncertainty level $\sim 75 \%$ of the land parcels achieve or exceed an allocation probability of $75 \%$, whereas for the $50 \%$ uncertainty level only $\sim 50 \%$ of the land parcels achieve or exceed an allocation probability of $75 \%$. The implication for spatial planning is that the optimal allocation of land use to some land parcels becomes increasingly uncertain with greater variation in the input performance scores (here: nitrate leaching rates). Figure 1 also reflects this observation. It shows maps of allocation probabilities for sheep and beef and beef based on nitrate leaching rates associated with $30 \%$ uncertainty. Land parcels outlined in red represent sheep and beef and beef farming respectively for the 2011 reference land-use configuration. The maps allow planners to assess visually how well certain land uses are located in the area for minimising nitrate leaching. They also show which land parcels are potentially better suited to minimise nitrate leaching and with how much certainty this can be assumed. Specifically, the allocation probability map for sheep and beef farming lets planners identify prime farming areas with great certainty. Furthermore, the maps indicate that allocation probabilities also vary significantly among land uses. Whereas sheep and beef farming shows an allocation probability of $94 \%$ at the $30 \%$ uncertainty level, beef farming showed only a maximum allocation probability of $36 \%$. Of course, the presented results are only indicative and only account for one single objective, whereas in a real world planning exercise more criteria would have to be taken into account. Furthermore, the presented allocation probabilities are a result of the particular error representation used in this study. For example, the use of a Gaussian error distribution (e.g. Thorsen et al., 2001), truncated at the error margins of the individual uncertainty levels, would have led to overall higher allocation probabilities because of the smaller sampling variability. However, since the main focus of this study was not to precisely model the error associated with nitrate leaching rates, but rather to explore the robustness of spatial land-use optimisation against variation in the input data, we used a uniform error distribution to represent greater variability.

\subsection{Optimal land use pattern sensitivity to variation of optimisation constraints}

The observed sensitivity of the land-use configuration to variation in the optimisation constraints is in general smaller than the observed sensitivity for the variation of input data (i.e. nitrate leaching rates). This is attributed to the smaller variance of the nitrate leaching rates on which the optimisation runs were based. For $\sim 93 \%$ of the considered land parcels, only two different land uses were allocated to anyone land parcel across the nine different optimisation runs. The overall mean allocation probability amounted to $79 \%$ (Table 3). However, the observed maximum potential reduction of total nitrate leaching $\left(\mathrm{kg} \mathrm{yr}^{-1}\right)$ by $71 \%$ (Table 3) was considerably higher than the observed maximum
Table 3. Landscape performance change and landuse allocation probability as response to optimisation constraints variation.

\begin{tabular}{|c|c|c|}
\hline $\begin{array}{c}\text { Constraints } \\
\text { variation (\%) }\end{array}$ & $\begin{array}{c}\text { Total nitrate } \\
\text { leaching }\left(\mathrm{kg} \mathrm{yr}^{-1}\right)\end{array}$ & $\begin{array}{c}\text { Mean change of total } \\
\text { nitrate leaching (\%) }\end{array}$ \\
\hline 10 & 1934770 & -14 \\
\hline 5 & 1799760 & -20 \\
\hline-5 & 1567720 & -30 \\
\hline-10 & 1456890 & -35 \\
\hline-15 & 1349490 & -40 \\
\hline-20 & 1244000 & -45 \\
\hline-30 & 1039870 & -54 \\
\hline-40 & 845306 & -63 \\
\hline-50 & 661027 & -71 \\
\hline \multicolumn{2}{|c|}{ Mean allocation probability: $79 \%$} \\
\hline Minimum allocation probability: $22 \%$ \\
\hline
\end{tabular}




\section{Sheep and beef}

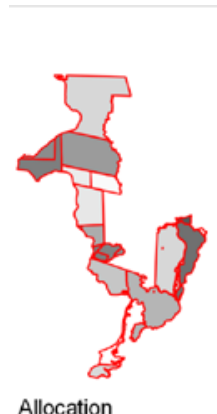

Probability [\%]

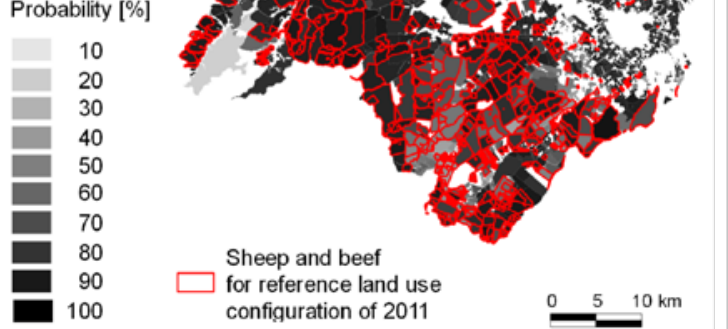

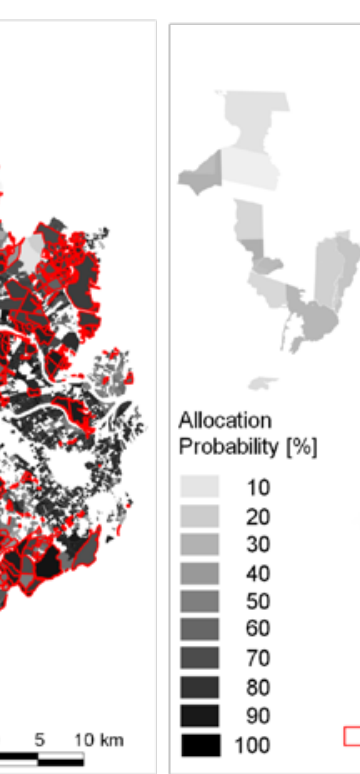

\section{Beef}

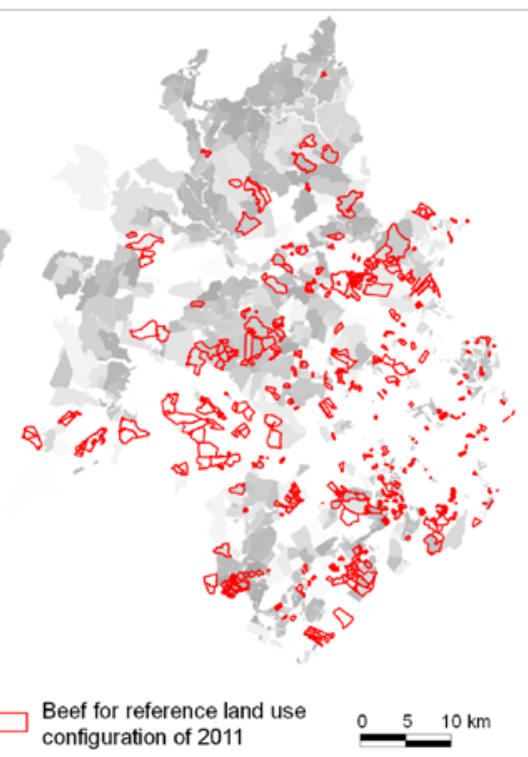

Performance Score Uncertainty: $30 \%$

Figure 1. Allocation probability maps for sheep and beef (left) and beef (right) for the uncertainty level of $30 \%$.

potential reduction by 38\% due to the uncertainty of the input data (Table 2). For our case study area, results suggest that the impact on optimal land-use pattern from constraints variation (as represented by the mean allocation probability) is, on average, not as great as the impact from uncertainty in the input performance scores (for uncertainties levels greater than 10\%).

\section{CONCLUSIONS}

Uncertainty of input performance scores for spatial optimisation can lead to an overestimation of the actual benefit of spatial optimisation. In the Heretaunga case study area the potential spatial optimisation benefit was overestimated by more than $5 \%$ points for uncertainty levels of more than $20 \%$. Uncertainty associated with the optimisation performance scores had overall greater impact on the uncertainty of optimal land-use allocation than the variation of optimisation constraints. Maps of maximum allocation probabilities help identify hot spot areas for targeted land-use development and change.

\section{ACKNOWLEDGEMENTS}

We acknowledge Hawke's Bay Regional Council for their support to carry out this study and for the provision of data for the Heretaunga case study area. We thank Fraser Morgan for his comments and suggestions to improve the manuscript.

\section{REFERENCES}

Aerts, J.C.J.H., Heuvelink, G.B.M., Goodchild, M.F. (2003). Accounting for spatial uncertainty in optimization with spatial decision support systems. Transactions in GIS, 7, 211-230.

Ausseil, A.-G.E., Herzig, A., Dymond, J.R. (2012). Optimising land use for multiple ecosystem services objectives: a case study in the Waitaki catchment, New Zealand. In: Seppelt, R., Voinov, A.A., Lange, S., Bankamp, D. (eds.), International Environmental Modelling and Software Society (iEMSs) 2012 International Congress on Environmental Modelling and Software. Managing Resources of a Limited Planet: Pathways and Visions under Uncertainty, Sixth Biennial Meeting, Leipzig, Germany.

Ausseil, A.-G.E., Dymond, J.R., Kirchbaum, M.U.F, Andrew, R.M, Parfitt, R.L (2013). Assessment of multiple ecosystem services in New Zealand at the catchment scale. Environmental Modelling and Software, 43, 37-48.

Beech, T., Dowd, M., Field, C., Hatcher, B., Andrefouet, S. (2008). A stochastic approach to marine reserve design: Incorporating data uncertainty. Ecological Informatics, 3, 321-333. 
Herzig et al., Sensitivity of land-use pattern optimisation to variation of input data and constraints

Berkelaar, M., Eikland, K., Notebaert, P., (2004). lp_solve version 5.5 - open source (mixed-integer) linear programming system. http://groups.yahoo.com/group/lp_solve (accessed 06/08/2013).

Beukes, P.C., Scarsbrook, M.R., Gregorini, P., Romera, A.J., Clark, D.A., Catto, W. (2012). The relationship between milk production and farm-gate nitrogen surplus for the Waikato region, New Zealand. Journal of Environmental Management, 93, 44-51.

Dymond, J.R., Ausseil, A.-G.E., Herzig, A., Parfitt, R. (2013). Nitrate and phosphorus leaching in New Zealand: a national perspective. New Zealand Journal of Agricultural Research, 56, 49-59.

Groot, J.C.J., Rossing, W.A.H., Jellema, A., Stobbelaar, D.J., Renting, H., van Ittersum, M.K. (2008). Exploring multi-scale trade-offs between nature conservation, agricultural profits and landscape quality A methodology to support discussions on land-use perspectives. Agriculture, Ecosystems \& environment, 120, 58-69.

Herzig, A. (2008). A GIS-based module for the multiobjective optimisation of areal resource allocation. In: Friis-Christensen, L., Pundt, H., Compte, I. (eds.), Proceedings of the 11th AGILE International Conference on Geographic Information Science, University of Girona, Spain.

Herzig, A., Ausseil, A.-G.E., Dymond, J.R. (2013). Multi-objective spatial optimisation for multiple outcomes. Landcare Research Contract Report LC1494, prepared for Hawke’s Bay Regional Council, New Zealand.

Herzig, A., Ausseil, A.-G.E., Dymond, J.R. (in press): Spatial Optimisation of Ecosystem Services. In Dymond, J.R. (ed.), Ecosystem Services in New Zealand - conditions and trends. Manaaki Whenua Press, Lincoln, New Zealand.

Lautenbach, S., Volk, M., Strauch, M., Whittaker, G., Seppelt, R. (2012). Quantifying trade-offs between bioenergy production, food production, water quality and water quantity. Aspects in a German case study. In: Seppelt, R., Voinov, A.A., Lange, S., Bankamp, D. (eds.), International Environmental Modelling and Software Society (iEMSs) 2012 International Congress on Environmental Modelling and Software. Managing Resources of a Limited Planet: Pathways and Visions under Uncertainty, Sixth Biennial Meeting, Leipzig, Germany.

Leathwick, J., Wilson, G., Rutledge, D., Wardle, P., Morgan, F., Johnston, K., McLeod, M., Kirkpatrick, R. (2003). Land environments of New Zealand. Auckland, David Bateman. 184 p.

Ledgard, S.F., Waller, J.E. (2001). Precision of estimates of nitrate leaching in OVERSEER®. Report FertResearch. Ruakara, AgResearch. 16 p.

Lilburne, L., Webb, T., Ford, R., Bidwell, V. (2010). Estimating nitrate-nitrogen leaching rates under rural land uses in Canterbury. Report No R10/127. Christchurch, Environment Canterbury. 37 p.

Meyer, B.C., Grabaum, R. (2008). MULBO: Model framework for multicriteria landscape assessment and optimisation. A support system for spatial land use decisions. Landscape Research, 33, 155-179.

Ministry of Works and Development (1981). Stock carrying capacities and fertilizer data for the North Island. Aokautere internal report No. 22. Wellington, Aokautere Science Centre, National Water and Soil Conservation Organisation, Ministry of Works and Development.

Murray, A.T. (2003). Site placement uncertainty in location analysis. Computers, Environment and Urban Systems, 27, 205-221.

Polasky, S., Nelson, E., Camm, J., Csuti, B., Fackler, P., Lonsdorf, E., Montgomery, C., White, D., Arthur, J., Garber-Yonts, B., Haight, R., Kagan, J., Starfield, A., Tobalske, C. (2008). Where to put things? Spatial land management to sustain biodiversity and economic returns. Biological Conservation, 141, 1505-1524.

Seppelt, R., Voinov, A.A. (2002). Optimization methodology for land use patterns using spatially explicit landscape models. Ecological Modelling, 151, 125-142.

Thorsen, M., Refsgaard, J.C., Hansen, S., Pebesma, E., Jensen, J.B., Kleeschulte, S. (2001). Assessment of uncertainty in simulation of nitrate leaching to aquifers at catchment scale. Journal of Hydrology, 242, 210-227.

Wei, R., Murray, A.T. (2012). An integrated approach for addressing geographic uncertainty in spatial optimization. International Journal of Geographical Information Science, 26, 1231-1249. 